\title{
Early Age Creep and Relaxation of UHPFRC under Low to High Tensile Stresses
}

${ }^{\mathrm{a} A g n i e s z k a}$ Switek-Rey*, ${ }^{\mathrm{b}}$ Emmanuel Denarié, ${ }^{\mathrm{b}}$ Eugen Brühwiler

${ }^{a}$ G2C Institute, HEIG-VD, Haute Ecole d'Ingénierie et de Gestion du Canton de Vaud, Yverdon-lesBains, CH-1014, formerly at: Laboratory of Maintenance, Construction and Safety of Structures, MCS-IIC-ENAC, EPFL - Ecole Polytechnique Fédérale de Lausanne, CH-1015, Lausanne, Switzerland, where this research was performed

${ }^{b}$ Laboratory of Maintenance, Construction and Safety of Structures, MCS-IIC-ENAC, EPFL - Ecole Polytechnique Fédérale de Lausanne, CH-1015, Lausanne, Switzerland

\section{Abstract}

This paper presents experimental results on creep and relaxation of UHPFRC at early age ( 3 to 8 days), under low to high tensile stresses $(1.2,2.7,5.4$, and $8.1 \mathrm{MPa}$ - estimated as $13,30,60$, and 90 $\%$ of the tensile strength respectively) up to the strain hardening domain. Various loading programs (single and incremental loading steps) were used to reveal non-linear viscoelasticity. For a very low load level of 1.2 MPa an unexpected important decrease of the creep response was observed. For the 2.7 MPa load level the viscoelastic responses obtained for creep and relaxation were in the same range. Non-ageing linear viscoelastic models were used to analyze and discuss the obtained results. Non-linear viscoelasticity was observed in several test series and possible underlying mechanisms were discussed. The hypothesis of shrinkage being the same for free and loaded specimen remains an open question for the analysis of test results.

Keywords: UHPFRC, tensile creep, tensile relaxation, early age, TSTM

\section{Introduction}

Ultra-High Performance Fiber Reinforced Concretes (UHPFRC) are very well adapted for the improvement of load carrying and protective functions of existing structures, because of their high durability, very low permeability, and outstanding mechanical properties with a strain hardening behavior in tension for specially tailored formulations, [1]

Corresponding author: Agnieszka Switek-Rey

Tel. +41216932893 ; mail: agnieszka.switek@a3.epfl.ch 
In composite UHPFRC-concrete structures, a UHPFRC reinforcing and/or protective layer sealed by the bituminous pavement undergoes intensive early age volume changes due to hydration reactions: thermal effects, and autogenous shrinkage. These deformations are restrained by both the existing support and reinforcement bars in the UHPFRC if any. Such restrained conditions lead to the development of high tensile eigenstresses, [2-4]. The strain hardening capacity of high end UHPFRC is able to mitigate the effect of these eigenstresses in most cases. Only in very special cases of detrimental fiber orientation, the eigenstresses can lead to premature early age localized macrocracking leading to increased permeability and reduced mechanical and protective performance. The viscoelastic potential in tension of UHPFRC plays a major positive role to relax early age eigenstresses due to restrained shrinkage, [5]. However, depending on the stress level, this relaxation might be associated to non-linear viscoelastic effects with cracking induced damage. Consequently, it should be investigated to optimize UHPFRC use in cast-on site structural applications.

The time-dependent behavior under high sustained tensile loads of UHPFRC at early age is difficult to determine since complex effects interact with each other: ongoing hydration and ageing, stress level, loading history and their couplings.

Till now little attention has been dedicated to this topic, and tensile creep and relaxation behaviors remain largely unknown for UHPFRC, especially at early age.

Further, various recent results highlight the difficulty to separate tensile creep from autogenous shrinkage [6-8]. The complex interaction of their underlying phenomena are discussed in [8-10]. Few experimental investigations on UHPFRC viscoelastic behavior in compression were performed by $[3,8]$ and [10-15], and in tension by [15-17]. The compressive creep response of UHPFRC without thermal treatment is significantly lower than that of ordinary concretes at a similar loading age and load level, [9] and [12-17]. The basic compressive creep coefficient of UHPFRC without thermal treatment, for a loading age of 28 days, at a low load level below $40 \%$ of the compressive strength, is typically 0.8 to 1 , instead of 2 to 4 for normal concretes [15]. Similarly to normal concretes, the 
viscoelastic response of UHPFRC shows ageing with a basic creep coefficient (under compression) at resp. 1, 4, 7, 28 days of resp. 2.27, 1.8, 1.57, 1.08 after [13].

Tensile creep of UHPFRC without heat treatment, under both sealed and drying conditions for loading at 7 days are close, in tension and compression, for load levels below $30 \%$ of the strength $(20 \%$ higher tensile vs compressive creep coefficient after 40 days,) according to Switek [20], in comparison with results of Kamen [5] on a similar mix. The same trend was observed by Rossi et al. [8] on a UHPFRC, for a loading at 7 days, under sealed conditions, with a creep of $39 \mu \mathrm{m} / \mathrm{m} . \mathrm{MPa}$. under tension compared to 21-30 $\mu \mathrm{m} / \mathrm{m}$.MPa under compression, at an age of 30 days. At the contrary, under drying conditions, for a loading at 7 days, Garas et al [17] measured a much larger creep under tension than compression (17 x larger after 30 days, with a tensile creep of $125 \mu \mathrm{m} / \mathrm{m}$.MPa under tension and around $7 \mu \mathrm{m} / \mathrm{m}$.MPa under compression) for a UHPFRC without thermal treatment loaded at 7 days age and for theoretical tensile and compressive load levels of $40 \%$.

Some first results for early age tensile creep of UHPFRC were obtained by $[4,18,19]$ in incremental

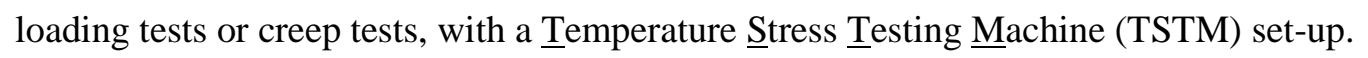

The TSTM set-up developed at MCS-EPFL by Kamen et al. [2, 5] was used for extensive experimental study $[2,20,21]$ to investigate the early age tensile response (creep and shrinkage) of strain hardening UHPFRC under various temperatures and loading conditions.

This paper focuses on the creep and relaxation response of UHPFRC in tension at early age, between 3 to 8 days, at various stress levels, under quasi-isothermal temperature conditions at $20{ }^{\circ} \mathrm{C}$, determined by means of a TSTM set-up. The results are then analyzed by means of non-ageing linear viscoelastic models in a first step. The obtained responses are finally compared and discussed in the perspective of the underlying mechanisms of creep and autogenous shrinkage at early age and specific aspects of UHPFRC hydration influence on creep.

Until now no such extended experimental database of results for tensile creep and relaxation at early age existed for UHPFRC materials. 


\section{Material}

The UHPFRC (type CM 22_TKK) used in this research is based on CEMTEC multiscale $\bigcirc$ fibrous mixes with two types of steel fibers: micro (steel wool) and macro (straight, smooth, $\mathrm{l}_{\mathrm{f}}=10 \mathrm{~mm}, \mathrm{~d}_{\mathrm{f}}=0.2 \mathrm{~mm}$ ) with a total dosage of $706 \mathrm{~kg} / \mathrm{m}^{3}$. It exhibits a strain hardening behavior under tension in the range of 1 to $2 \%$ [20]. CEMTEC multiscale $\bigcirc$ mixes were originally developed at Laboratoire Central des Ponts et Chaussées (LCPC) [11, 22]. This material was modified and optimized in the framework of research held at MCS for rehabilitation applications on existing structures [23, 24]. The material has a very low water/binder ratio of $0.129,1392 \mathrm{~kg} / \mathrm{m}^{3}$ cement (CEM I 52.5 HTS from Le Teil - Lafarge), $362 \mathrm{~kg} / \mathrm{m}^{3}$ white microsillica (SEPR), $34.8 \mathrm{~kg} / \mathrm{m}^{3}$ Superplasticizer (Cementol Zeta Super S from TKK- Slovenia). The very high cement and silica fume dosages are motivated by a sufficient paste content to accommodate all the fibers, while retaining a self-compacting character. With such a very low water/binder ratio, not all cement and silica fume grains are hydrated and unhydrated ones act as inert filler with a potential self-healing capacity. The degree of hydration of this mix is close to $30 \%$ after 28 days $[5,21]$. The initial setting time estimated with ultra-sound velocity evolution measurements (FRESHCON system, [25]) is around 7-10 h, with final setting time of 29-36 h (for a velocity of 1500 $\mathrm{m} / \mathrm{s}$ ) after the contact of water with cement [20].

\section{Methodology}

\subsection{General}

The objective was to characterize the tensile viscoelastic behavior of UHPFRC at early age by means of creep and relaxation tests, under various stress levels and loading programs, and to get insights on the non-linearity of their delayed response by inducing high tensile stresses nearby the hardening domain. 
Sealed creep and relaxation tensile tests were performed in a TSTM set-up, on dogbone shaped specimens. Reliable relaxation tests under tension at early age, when shrinkage is intensively developing, are difficult to perform, and a TSTM machine with adapted special loading procedure, is a suitable testing setup for such type of tests. Quasi-isotherm temperature conditions at $20^{\circ} \mathrm{C}$ were insured with the help of a cooling circuit surrounding the molds of both free and restrained specimens. The quality control of the fresh mix was performed by means of mini-slump flow tests, [24], air content and ultra-sound velocity evolution measurements (FRESHCON system) to insure the same properties of different batches. It showed a very good reproducibility. Detailed results can be found in $[20]$.

Quasi-static tensile tests were firstly performed in the same TSTM set-up at 3 days of age to characterize the mechanical response in tension. The average ultimate tensile strength at 3 days $f_{u t, 3}$ was found to be on average $9 \mathrm{MPa}$ with a standard deviation of $0.25 \mathrm{MPa}$ [20]. This information was used to determine the loading program (stress levels and history) for creep and relaxation specimens.

\subsection{TSTM set-up}

The Temperature Stress Testing set-up used was developed at MCS in the framework of the doctoral thesis of Kamen [2, 5]. The cross section of the specimen is rectangular, 50 x $100 \mathrm{~mm}$, dimensions optimal for UHPFRC materials. It is composed of two devices with specimens of the same dog-bone geometry, sealed in the metal molds Fig. 1 . One allows free deformation measurements and consequently monitoring of free autogenous shrinkage. The second one is equipped with a force cell and an electromechanical actuator, which allows loading and measuring the reaction force and thus evolution of stresses. Further details about testing procedures can be found in [2,5] and [20].

\subsection{Loading programs}

-All loadings were applied on the restrained specimen from 3 days of age. Displacements were monitored on both specimens from casting on. A closed loop procedure with stroke displacement control between two boundaries of very low forces, one positive, the other one negative, helped keep 
the force level close to $0 \mathrm{kN}$ within a margin of $\pm 0.05 \mathrm{kN}( \pm 0.01 \mathrm{MPa})$ until 3 days of age. This iterative procedure applied before setting, from $17 \mathrm{~h}$ after the moment of pouring, until loading at $72 \mathrm{~h}$ was thus active (reacting to specimen response) although without danger of losing control due to the very low material stiffness at the beginning of this time frame, that would make a real force control hardy usable. The path of stroke displacements according to this procedure, as well as the variation of the residual force within the fixed limits in the time frame before loading depends on the evolution of material stiffness before and shortly after setting and on the initial force acting on the specimen when the procedure starts at $17 \mathrm{~h}$ age. It and can vary significantly within the fixed limits from one test to the other due to differences in swelling phases and setting times or initial force at $17 \mathrm{~h}$ age as can be seen comparing the results on Fig. $6 \mathrm{~b}$ and $8 \mathrm{a}$ for the strains in the restrained specimen FL 21 and FL_22, prior to $72 \mathrm{~h}$. It however guarantees in a very efficient way that the force on the specimen remains close to 0 as shown on Fig. $6 a$ and 8 b, thus having no effect on the subsequent creep or relaxation tests.

- Firstly, two series of creep and relaxation tests with single step loading were performed. In each series total three specimens were loaded from 3 days of age during 8 days, with stress or deformation level imposed respectively, corresponding to $2.7,5.4$, and $8.1 \mathrm{MPa}$, estimated as 30, 60, and $90 \%$ level of the ultimate tensile strength respectively, Table 1. Accidentally, one additional creep test was realized at a load level of $1.2 \mathrm{MPa}$ (estimated $13 \%$ of the ultimate tensile strength), and is also reported and discussed in the sequel. During each creep and relaxation test, the shrinkage was monitored on a free specimen from the same UHPFRC mix, with the same geometry, and subjected to the same temperature control.

Loading for the creep tests was performed by using force control with a rate of $0.5 \mathrm{kN} / \mathrm{s}(0.1 \mathrm{MPa} / \mathrm{s})$. Creep curves were obtained by subtracting free shrinkage to the total deformation of the loaded specimen (assuming the superposition principle of creep and shrinkage deformation applies), since creep deformation in tension was considered as positive and the one of shrinkage was negative. 
For relaxation tests, the displacement rate of $0.001 \mathrm{~mm} / \mathrm{s}\left(1.3310^{-6} 1 / \mathrm{s}\right)$ was used for loading, which was similar to the rate of loading for creep tests. After reaching the value of force corresponding to the target tensile stress level, deformation control was used for relaxation. Then, every 10 minutes, the initially imposed deformation was reduced by the value of shrinkage measured on the parallel free specimen. The assumption made was that the shrinkage of the loaded and free specimens are the same. -Secondly, incremental creep and relaxation tests were performed by increasing stepwise the level of imposed sustained stress or deformation, to gradually approach the strain hardening domain and detect the onset of non-linear viscous phenomena. The age at loading was 3 days. Specimens were loaded in six successive steps of $24 \mathrm{~h}$ each, corresponding to the initial stress levels of 2.7, 4.0, 5.4, 6.7, 8.1, and 9.5 MPa, until 9 days of age,

Table 2. Two specimens in creep: FL_21, FL_24 and one in relaxation: FL_22 were tested. Conditions for loading and sustained load steps were the same as for creep and relaxation in single step tests, presented above.

\section{Experimental results - Single step loading}

\subsection{Creep tests}

The total deformation curve decreases for all stress levels, as it is shown on

Fig. 2 .

The lower the stress level is, the more the total deformation curve decreases. For 1.2 MPa stress level the total deformation curve started to decrease immediately after the loading, for $2.7 \mathrm{MPa}$ after few hours, and later for higher stress levels. The value of free shrinkage deformation was in the same range for all monitored shrinkage specimens in parallel to the loaded ones,

Fig. 2 and Fig. 4.

The specific creep curves were obtained by dividing the creep deformation by the imposed stress level. The specific creep deformation for three principal stress levels is shown on Fig. 3. The rate of the 
specific creep deformation was higher for a higher load level. The instantaneous deformation for all creep tests was proportional to the imposed stress level, and was $20 \mu \mathrm{m} / \mathrm{m} / \mathrm{MPa}$, which corresponds to an elastic modulus of $1 / 20 * 10^{-6}=50^{\prime} 000 \mathrm{MPa}$, with no non-linear behavior during the loading part. The delayed deformation under constant force was clearly non-linear for 5.4 and 8.1 MPa investigated stress levels, Fig. 3. For the low stress level of $2.7 \mathrm{MPa}$, at about $170 \mathrm{~h}$ age, the creep deformation started slightly to decrease. For medium stress level it stabilized at around $200 \mathrm{~h}$, and for high stress level it showed a clear tendency to increase, but the experiment was conducted until $190 \mathrm{~h}$ and then stopped. Similar non-linearity in creep deformation was observed between the two medium and high stress levels compared to the low stress level, showing a difference of around $6 \mu \mathrm{m} / \mathrm{m} / \mathrm{MPa}$ at $190 \mathrm{~h}$, Fig. 3.

For a very low stress level of 1.2 MPa, representing $13 \%$ of $\mathrm{f}_{\mathrm{Ut}}$ at 3 days of age, the specific creep deformation decreased shortly after $10 \mathrm{~h}$ of sustained load, Fig. 4b. Since physical concept of creep deformation does not allow a decrease of deformation under imposed constant stress, this puts into question the superposition principle of creep and shrinkage between loaded and free specimen respectively for this very low load level and requires further analysis.

\subsection{Relaxation tests}

Relaxation of stresses for specimens loaded with three different deformation levels are presented on Fig. 5a. Most of stress relaxation occurred during two days after loading. The relative relaxation curves were obtained by dividing the stress evolution by the imposed deformation (adjusted by recorded in parallel free shrinkage), and are presented on Fig. 5b. Within the timeframe of the test, for an increase of a load level of $30 \%$ and $60 \%$ the relative relaxation did not increase proportionally. For a low initial stress level of $30 \%$ the relaxation was around a half compared to higher load levels. The most intensive relaxation occurred during the first 2 days, and then the rate of relaxation decreased, contrary to what has been shown for creep tests, whereas the rate of specific creep delayed response was almost proportional to the imposed stress level, Fig. 3. 
Page 9 of $\mathbf{3 9}$ 


\section{Experimental results- Incremental loading}

\subsection{Creep test}

Results for incremental creep tests are presented on Fig. 6 and Fig. 7, for stress and deformation of loaded creep and free shrinkage specimens. Fig. 6a shows the stresses and Fig. $6 \mathrm{~b}$ the strains in the free and restrained specimen FL_21, both before and after loading at $72 \mathrm{~h}$. The strains in the restrained specimen prior to loading correspond to the loading program applied to keep the force close to 0 (see $\S$ $3.3)$.

In order to investigate the non-linearity in the viscoelastic response for increasing stress levels, graphs with relative creep responses are presented on Fig. 7 for specimens FL_21 and FL_24. Relative creep curves were obtained by dividing the deformation recorded during a sustained stress step by the initial stress value from this step. Specimen FL_21 was loaded with 4 stress steps until $6.7 \mathrm{MPa}$ and specimen FL_24 with 6 stress steps until 9.5 MPa,

Table 2 .

Results for incremental creep steps 1 to 4 for specimen FL_21 and 1 to 3 for specimen FL_24 show that even if the stress level is higher, the relative creep deformation is less pronounced, and thus the history effect dominates. Relative creep deformation during the first creep step is the highest for both creep specimens until step 4. For specimen FL_21 the last (fourth) creep step corresponding to 6.7 MPa showed the smallest relative creep deformation. For specimen FL_24 the tendency was the same until the 4th load step, where this tendency was reversed and step 5 showed pronounced non-linear viscoelastic behavior, and consequently higher relative creep curve.

For specimen FL_24, step 4 already shows a relative creep higher than that of step 3, and markedly higher for step 5. This indicates a shift form linear to non-linear viscous response under force control around 6 to $7 \mathrm{MPa}$, at an age of $150 \mathrm{~h}$. 
During the loading of specimen FL $\_24$, rupture occurred from $5^{\text {th }}$ to $6^{\text {th }}$ stress level, which confirms that $6^{\text {th }}$ stress level was situated in the strain hardening domain. Unfortunately, during the loading of specimen FL_21 a power cut interrupted the test during the $4^{\text {th }}$ stress level, before reaching the nonlinear domain, making the confirmation of the onset of a nonlinear viscoelastic response impossible with this specimen. However, Denarié, $[26,27]$ showed that for incremental creep and relaxation tests on wedge splitting specimen, at various load levels, conducted on concrete, the deviation from linear viscoelasticity was repetitive on a set of 3 specimens tested in similar conditions, following the same incremental loading procedure. Similar tests of incremental tensile creep can be performed for other UHPFRC mixes, and load levels should be adapted in function of quasi-static tensile response: max. stress level, and span of stresses of the hardening domain.

\subsection{Relaxation test}

Results for incremental relaxation tests are presented on Fig. 8, for stress and deformation of loaded relaxation and free shrinkage specimen. Fig. 8a shows the strains in the free and restrained specimen, FL_22 both before and after loading at $72 \mathrm{~h}$ and Fig. $8 \mathrm{~b}$ the stresses. The strains in the restrained specimen prior to loading, Fig. 8a correspond to the loading program applied to keep the force close to 0 (see $\S 3.3$ ). The large difference in the positive strains observed prior to loading with respect to specimen FL_21, Fig. 6b, are due to the different path taken by the iterative procedure to keep the force level close to zero, likely to be due to the different forces acting on the specimen when the procedure started (-0.01 kN for FL_21 and $-0.03 \mathrm{kN}$ for FL_22). Nevertheless, despite large positive strains up to $400 \mu \mathrm{m} / \mathrm{m}$, the force level (compression or tension) remained extremely low, within the fixed boundaries before loading as shown on Fig.8b, without any significant effect on the viscous response after loading at $72 \mathrm{~h}$.

In order to investigate the non-linearity in viscoelastic response for increasing stress levels, graphs with relative stress relaxations are presented on Fig. 9 for specimen FL_22. Relative relaxation curves were obtained by dividing the stress relaxation recorded during a sustained load step by the initial value of stress from this step. 
Relative stress relaxation during the first load step is the most pronounced. For increasing load level, the relative relaxation is less pronounced, showing the dominance of the history effect on non-linearity in this range of stress levels.

\section{Analysis with linear viscoelastic models}

\subsection{General}

The objectives of the analysis were to:

- determine more accurately the linear and non-linear viscoelastic ranges in incremental creep and relaxation responses for loading age of 3 days, -provide parameters of non-ageing generalized Maxwell model for prediction of relaxation, and Kelvin model for prediction of creep under low load level, -to highlight differences of viscoelastic potential from creep and relaxation tests.

The evolution of the degree of hydration was determined by means of SEM image analysis [28,29]. It is the most important during the first 3 days, and then stabilizes from 3 to 7 days and beyond, Fig. 10 and [21]. For that reason, non-ageing linear viscoelastic models have been used for analysis. Parameters of non-ageing generalized Kelvin model (Eq. 1) for creep and non-ageing generalized Maxwell model (Eq. 2) for relaxation have been determined on the basis of the creep and relaxation tests under the low stress level of $30 \%$ for which they are assumed to be valid; with: $\sigma_{0}$-imposed stress level for creep; $\varepsilon_{0}$-imposed strain level for relaxation; $\mathrm{J}\left(\mathrm{t}, \mathrm{t}_{0}\right)$-creep compliance function; $\mathrm{R}\left(\mathrm{t}, \mathrm{t}_{\mathrm{o}}\right)$ relaxation modulus, which corresponds to the relaxation of stress under a unit strain; t-age of the specimen; $\mathrm{t}_{0}$-age of specimen at loading; $\tau$-retardation time; E- modulus of elasticity. More detailed description of the models can be found in $[20,31]$. The deviation of curves predicted with linear viscoelastic models from experimentally obtained ones, indicates the likely non-linear creep or relaxation behavior. The viscoelastic potential from relaxation and creep tests could also be compared by transformation of creep curves into relaxation curves, with use of the Bažant algorithm [30]. 


$$
\begin{gathered}
\varepsilon\left(t, t_{0}\right)=\sigma_{0} \cdot J\left(t, t_{0}\right), \text { with } J\left(t, t_{0}\right)=\frac{1}{E_{0}\left(t_{0}\right)}+\sum_{k=1}^{n} \frac{1}{E_{k}\left(t_{0}\right)}\left(1-e^{\frac{t-t_{0}}{\tau_{k}}}\right) \\
\sigma\left(t, t_{0}\right)=\varepsilon_{0} \cdot R\left(t, t_{0}\right), \text { with } R\left(t, t_{0}\right)=E_{\text {tot }}\left(t_{0}\right) \sum_{i=1}^{n} \frac{E_{i}\left(t_{0}\right)}{E_{\text {tot }}\left(t_{0}\right)} \cdot e^{\frac{t-t_{0}}{\tau_{i}}}
\end{gathered}
$$

with $E_{\text {tot }}\left(t_{0}\right)=\sum_{k=1}^{n} E_{k}\left(t_{0}\right)$

\subsection{Creep tests: $30 \%$ stress level}

Parameters for a generalized Kelvin model were estimated on the basis of the results of tests FL_8 and FL_24 for $30 \%$ stress level, over $24 \mathrm{~h}$ Fig. 11, and are presented in

Table 3 for an average creep response (set 1 ). Only two chains with $\tau_{\mathrm{k}}=1$ and $10 \mathrm{~h}$ were needed to correctly simulate the obtained incremental creep over 24 h of test FL_8 and FL_24. The relative creep results for the two specimens loaded at the age of 3 days are presented on Fig. 11 together with the predictions of the generalized Kelvin model. The correlation between simulation and experimental results was very close.

\subsection{Creep test: incremental loading}

On Fig. 12 four steps of the incremental creep test FL_21 are presented. Kelvin model parameters were determined for the first step corresponding to the low load level, and following steps for increasing load levels were predicted with the same linear model, see Table 3, set 2 .

These parameters are different from those determined for specimen FL_24.

Final setting based on an ultrasound velocity of $1500 \mathrm{~m} / \mathrm{s}$ varied between 29 and 36 hours, thus loading at 72 hours took place between 36 and 43 hours after final set, depending on the specimen. This difference could explain the relatively large scatter observed in the viscous response from the first loading steps in all tests shown on Figure 16 for all tests, and which is less and less the case for the subsequent response for further loading steps in the linear range, at later ages, as can be seen 
comparing Figures 12 and 13a. For this reason, it was decided to make separate determinations of Kelvin chains for tests FL_21 and FL_24 which exhibit significant differences in the viscous response for the first step.

All difference between experimental and modeled curves for subsequent loading steps after the first one would be a nonlinear viscoelastic behavior for a material with negligible ageing in the timeframe of the tests [27]. We can observe that for increasing load levels, the modeled relative steps decrease. This corresponds to the linear viscoelastic behavior expected from the model.

We can observe a similar trend for measured and modeled creep responses, where experimentally measured steps from 1 to 4 decrease, following in this way the linear viscoelastic behavior predicted before. The stress level corresponding to the last (fourth) load level was 6.7 MPa. The age of specimen during this 4 th loading step was $3+4=7$ days. No non-linearity was observed until 4 th loading step on specimen FL_21 loaded at 3 days of age. To verify where and if the non-linear threshold exist, another specimen was investigated with the same loading program until a higher stress level.

The experimental and modeled incremental creep curves are presented for specimen FL_24. On Figure 13 a) steps 1-3 are presented, where for increasing stress level the relative creep deformation decreases. Both modeled and experimental responses follow this decreasing tendency. This shows the linear viscoelastic response until 5.4 MPa.

On Figure 13 b) steps 3-5 are presented and we can observe that this trend changes. Experimental 4th creep step was slightly higher than the third one, which revealed the beginning of the non-linear viscoelasticity. The 5th experimental step showed much higher deformation than previous ones and much different from 5 th one predicted with linear model. The linear model prediction of steps 4 and 5 were very close and still with slightly decreasing tendency.

For this specimen FL_24 the non-linear viscoelastic threshold was around the 4th loading step corresponding to $6.7 \mathrm{MPa}$, and the age of the specimen during this 4th step was 7 days.

\subsection{Relaxation test: single step}

Parameters for a non-ageing generalized Maxwell model predicting the average response were determined and are presented in Table 4, on the basis of test results of specimen FL_19 and FL_22. 
Four chains of $0.1,1,10$ and $10000 \mathrm{~h}$ were used to predict the viscoelastic response over $24 \mathrm{~h}$, the last one acting virtually as a spring. The weight of chains is increasing from 0.1 to 10 monotonically. The chain of $10000 \mathrm{~h}$ was used to determine the final value of relaxation. The experimental and modeled results for two relaxation specimens loaded at age of 3 days are presented on Fig. 14. Over the period of time of $24 \mathrm{~h}$ the stress relaxation was recorded for low stress level. Two obtained results showed relative stress relaxation of 18 and $35 \%$ after $24 \mathrm{~h}$. This difference may be caused by variability in material properties such as fiber distribution and orientation or control of the test. No significant difference was observed between corresponding shrinkage deformations. The correlation for simulations 1 and 2 is very close with experimental results. These curves represent the range of relaxation response. The simulation showing the average response from these two results represents a probable stress relaxation response of the material loaded at 3 days.

\subsection{Relaxation test: incremental loading}

Incremental relaxation test was performed on specimen FL_22 at the age of 3 days. The relaxation response was modeled by using a linear generalized non-ageing Maxwell model fitted on the first loading step. Experimental and simulation results are presented on Fig. 15a for steps 1-3 and on Fig. $15 \mathrm{~b}$ for steps $3-6$. The amplitude of stress relaxation during the first loading step was around $15 \%$ after 4h and at the end of loading step after $24 \mathrm{~h}$ was around $35 \%$.

For all incremental steps the tendency of relative relaxation steps is the same for experimental and modeled results. With increasing stress level the relative relaxation curves show less and less relaxation. For all steps, measured and modeled curves are very close, which did not reveal clear nonlinear viscoelasticity in the incremental relaxation tests loaded at 3 days of age.

\subsection{Comparison of viscoelastic potential from creep and relaxation tests}

Creep and relaxation responses can be compared in the linear domain by using Bažant algorithm [30]. It is a step by step algorithm which allows by discretizing a creep curve, to transform it into stress relaxation curve in time. This method applies only to the domain of linear viscoelasticity. 
The creep curves from tests with a low load level at 3 days were transformed into relaxation and are presented on Fig. 16 for specimens FL_8, FL_21, and FL_24, respectively curves 1, 2, and 3. They were compared with stress relaxations obtained experimentally in relaxation test from specimens FL_19 and FL_22, curves 4 and 5 respectively. A range of relaxation response deduced from creep tests is between curves 1 and 2, and from relaxation tests between curves 4 and 5 . Both types of tests give the same range of viscoelastic potential of stress relaxation between 20 and $35 \%$ after $24 \mathrm{~h}$ for a loading from 3 days of age. This means that under imposed deformation corresponding to $2.7 \mathrm{MPa}$ (30\%) at 3 days of age, the relaxation of stresses is about $0.5-1 \mathrm{MPa}$ after $24 \mathrm{~h}$. The differences in results obtained for each type of test might be due to the variability of material, but this effect was the same for creep and relaxation tests. This confirms that for low load levels, in the linear viscoelastic domain, the viscoelastic potential obtained from creep and relaxation tests is in the same scatter band after $24 \mathrm{~h}$, for loading at 3 days of age.

\section{Discussion}

\subsection{Overview}

In view of the obtained results for the viscoelastic response of UHPFRC in tension, the influence of four key factors are shortly described and then discussed: ageing, early age volume changes, stress level and loading history, and several interpretations are discussed.

\subsection{Influence of ageing}

The estimation of stress levels is based on properties of material at 3 days of age, when $\mathrm{f}_{\mathrm{U}, \mathrm{t}}=9 \mathrm{MPa}$. The tensile strength of the material after a creep/relaxation test at 12 days of age was on average $\mathrm{f}_{\mathrm{U}, \mathrm{t}}=12 \mathrm{MPa}$, under quasi-static loading. When estimating the highest stress level of $9.5 \mathrm{MPa}$ representing $105 \%$ of the strength at 3 days, it corresponds to $79 \%$ at 12 days of age properties. Thus, the ageing of the mechanical properties of the tested material results in (1) a decrease of the real-time imposed stress level and (2) a less pronounced linear viscoelastic response for all load levels. Since the 
incremental creep and relaxation tests were conducted from 3 to 10 days of age through the loading steps of $24 \mathrm{~h}$ each, the effect of ageing could partially explain the observed reduction of viscoelastic response in incremental creep and relaxation tests, Fig. 7 and Fig. 9, together with a loading history influence. Cementitious materials exhibiting intensive early age volume changes are very sensitive to the age of loading. The viscoelastic response in creep or relaxation tests loaded earlier at 2 days of age, is expected to be much more non-linear, as shown by [18].

\subsection{Effect of early age volume changes}

In incremental relaxation test the largest difference for stress relaxation is between the first and the second loading step, Fig. 9. This is the phase that corresponds to the end of the intensive shrinkage evolution. Similarly to relaxation tests, such a trend was also observed in incremental creep tests, Fig. 7, where the first load level showed the most pronounced response.

During the first loading step the rate of shrinkage is the most intensive during the whole timespan of a sustained load test. From the $2^{\text {nd }}$ loading step the shrinkage rate is lower during following loading steps. This is interpreted here as the influence of early age volume changes due to ongoing hydration reaction (additionally and in parallel to loading history and ageing effects) on more pronounced nonlinearity of viscoelastic response observed for incremental creep and relaxation tests.

Similarly the single step creep and relaxation tests showed a pronounced viscoelastic response at the beginning of the test, during first 2 days corresponding to intensive early age changes, after which the rate was lower, Fig. 3 and Fig. 5. It is interesting also to notice that the instantaneous part of deformation was proportional to the imposed stress, and only the delayed response showed a nonlinearity, which indicates an interaction between creep deformation under constant load and early age on-going volume changes.

The UHPFRC in its early age undergoing hydration reaction is very sensitive to the age of loading. For specimens loaded at early age, the mechanical properties depend on the progress of ongoing hydration reaction, and consequently early age changes. The interaction of viscoelastic response with those intensive early age changes might lead to an "early age hydration induced" non-linearity. 
Loukili [12] showed that due to intensive shrinkage, early age volume changes occurred during first 810 days for two types of tested high performance concretes: RPC (Reactive Powder Concrete) and CRC (Compact Reinforced Concrete), which corresponds to the age of specimens tested in presented study. Additionally it was observed that after application of heat treatment accelerating the hydration reaction, the autogenous shrinkage and creep deformations were significantly reduced, which confirms the influence of on-going hydration reaction on more pronounced early-age viscoelastic response.

These intensive early age changes are closely linked to water consumption for hydration reaction, and stabilize when the relative humidity reaches $73 \%$ according to Loukili [12], for a similar UHPFRC mix. Kamen [5] showed the evolution of degree of hydration for a closely related material, and Kazemi-Kamyab [21] for the UHPFRC presented in this paper, where the most of evolution of the degree of hydration occurred during the first 8 days, with a full consumption of the capillary water within the first 24 hours after final setting. These studies confirm that the most intensive early age volume changes occur until 3 days of age. As for the results presented in this paper, UHPFRC specimens were loaded at 3 days of age, their viscoelastic response is most probably affected by this critical and sensitive loading age, during the final phase of intensive early age volume changes.

\subsection{Stress level and damage activation influence}

NB: High stresses are defined here as above $60 \%$ of the average tensile strength of the UHPFRC under investigation, at the age of loading. According to literature, this is also a stress level corresponding to onset of a non-linear viscous response in concretes under tensile loading mentioned by several authors [32-34].

For incremental creep and relaxation tests there is less viscoelastic response for the first successive stress levels, Fig. 7. This tendency was observed during whole relaxation, but for high stress level in creep test the viscoelastic response was more pronounced from the $4^{\text {th }}$ load level $(6.7 \mathrm{MPa})$, Fig. 7 . This could be explained by the activation of additional mechanism, like microcracking induced damage, in creep tests (contrary to relaxation tests). Rossi et al. [35] revealed a correlation between damage detected by Acoustic Emission monitoring and creep deformation in concrete, also observed 
by Denarié et al. [26]. This leads to the hypothesis that for high stress levels approaching the hardening domain, there is at least an additional (damage induced) contribution to non-linear viscoelastic response for incremental creep tests.

There is no general agreement in the literature on the threshold stress level under tension above which cementitious materials exhibit a non-linear viscous response.

Two creep tests performed at 2.4 MPa stress level at 2 days age by Kamen [18] showed non-linear deformation already in the instantaneous part of loading, and more pronounced non-linear creep in delayed response. For these two similar UHPFRC mixes: CM22 [5, 18] and CM22_TKK [20] tested in tensile creep at 3 days, a difference can already be observed in instantaneous deformation, which was non-linear in [18] and linear for 3 stress levels in the present study. This indicates that non-linear effects, already in the instantaneous part, are more pronounced for the "younger"-less mature material CM22 for which the hydration was delayed by about $10 \mathrm{~h}$.

After $[36,37]$ the relaxation under tension is not significantly influenced by the stress level for concretes at early age. Gutsch et al. [36] investigated the tensile creep and relaxation response in a rigid test frame of concretes with different types of binders and w/c ratios between 0.42 and 0.65 , loaded at 1 and 7 days under sealed isotherm conditions at $20^{\circ} \mathrm{C}$. They reported no significant influence of the stress/strength ratio on the viscous response. The analysis of an incremental tensile creep test with a linear viscoelastic model reveals a deviation from linearity at the second loading step for a load level of $50 \%$ at 3 days, however not discussed by the authors. For relaxation, the stress decay after $100 \mathrm{~h}$ of loading varied between 45 to $58 \%$ for a loading at 1 day and 25 to $30 \%$ for a loading at 7 days age. The creep coefficient after 100 hours loading varied from 0.3 to 0.5 for a loading at 7 days to 0.5 to 1 for a loading at 1 day.

Denarié et al. [26] showed that relaxation starts to deviate from a linear response at load levels around $50 \%$ pre-peak in Wedge Splitting Tests on mortar. However, for this specific testing geometry with a strain gradient, the material enters the tensile softening domain at the notch tip for load levels close to 
$50 \%$. At this level, the deviation from non-linearity corresponds to the beginning of activation of the tensile strain softening (equivalent load level $100 \%$ under uniaxial tension).

Beushausen et al. [38] investigated the tensile relaxation response of mortars with a water cement ratio of 0.45 and 0.6 and of a commercial repair mortar. Tests were performed at 2, 7, and 28 days, with a load level of $80 \%$ of the tensile strength at the loading age, under uniaxial tension. Specimens were sealed with paraffin wax to prevent drying and associated shrinkage. The relaxation response after $72 \mathrm{~h}$ loading was the more pronounced with a lower age and higher w/c ratio. For a w/c of 0.45 , it was close to $35 \%$ of the initial stress level at 2 days and close to $20 \%$ at 7 and 28 days and $45 \%$, with a fast decay in the first hour (50\% at $1 \mathrm{~h}$ of the total relaxation at $72 \mathrm{~h}$ ). Kovler et al. [39] compared the creep response of sealed concretes loaded one day after casting, with and without silica fume with both a restrained shrinkage set-up and a creep test with constant load. Concretes with silica fume exhibited a higher basic creep at early age for a similar water/binder ratio. Shortening (total strain) of the specimen under tensile loading was observed due to the high autogenous shrinkage acting. Creep strains after taking the free shrinkage measurements into consideration showed a slightly decreasing trend after $168 \mathrm{~h}$.

Bissonnette et al. [32] investigated the tensile creep response of concretes with a w/c of 0.4, paste content of 27 and $35 \%$, with and without steel fibers, at a load level of 20 and $50 \%$ of the short term tensile strength, in drying and sealed condition. Ages at loading were 7 or 28 days. The creep response under sealed conditions was linear up to a load level of $50 \%$. An additional result for a load level of $67 \%$ is mentioned in the paper (although not presented), for which the basic creep response significantly deviated from linearity suggests a threshold load level value for deviation from linear viscoelasticity between 50 and $676 \%$ for the concrete investigated. Addition of fibers at a dosage of $40 \mathrm{~kg} / \mathrm{m}^{3}$ had no effect on shrinkage. However, it significantly influenced the creep response, with opposite effects of crimped and hooked fibers. Cheyrezy et al. [14], compared the creep response of RPC and CRC mixes with and without steel fibers. The addition of $2 \%$ vol. short discontinuous straight steel fibers decreased the autogenous shrinkage and basic creep of 20 to $25 \%$. Altoubat [40] found that steel fibers decreased the rate of basic creep of concrete. 
Atrushi [34] focused on the early age (age of loading between 1 and 8 days) tensile and compressive creep of High Performance Concretes (HPC) with w/b=0.4 (0.42) and compressive strength from 69 to $85 \mathrm{MPa}$ at 28 days and tensile strength from 4 to $4.7 \mathrm{MPa}$ at 28 days, at various load levels from 20 to $80 \%$ of the strength, and the associated stress relaxation. Additionally, the effect of various curing temperatures between 20 and $60^{\circ} \mathrm{C}$ was also investigated. Both tensile and compressive creep rigs and a TSTM set-up were used. The threshold limit of non-linear viscous response was around $60 \%$ to 70 $\%$ for basic tensile creep for a loading age of 3 days. Atrushi found always increasing tensile creep response under sealed conditions although the total strains exhibited a decreasing response after 1 day. Tensile creep kinetics are very different for compressive one, with an almost linear secondary creep phase with a much higher rate than in compression. Atrushi also questions the superposition principle of autogenous shrinkage and creep strains. Finally, Ostergaard [41] observed a nonlinear tensile creep response at 1 day for concretes with w/c $=0.5$, for load levels between 25 and $45 \%$ of the tensile strength at the age of loading.

\subsection{History of loading effect}

Another factor influencing the viscoelastic response is the history of loading. During the first loading step the viscoelastic response is the most pronounced and decreases for subsequent ones, Fig. 7 and Fig. 9. Even if the stress level increases with time in incremental testing, the first viscoelastic response is the most pronounced compared to the first ones close to the linear domain, before reaching very high stress level inducing pronounced non-linearity and damage. In order to determine more precisely if the observed viscoelastic behavior in incremental tests was linear or non-linear, further study with a use of more complex ageing viscoelastic models would be needed.

\subsection{Non monotonic creep}

For a very low stress level, in this study around $13 \%$ of $\mathrm{f}_{\mathrm{U}, \mathrm{t}}$, the creep deformation decreased in time, as shown in Fig. 4b. A similar trend at later ages can be observed in creep tests, at $30 \%$ load level, Fig. 3. Similar phenomena of a slight decrease of creep deformation was observed by Kamen [18] 
using the same testing setup-TSTM, to test UHPFRC loaded at 72h with 1.2 and $2.4 \mathrm{MPa}$, representing in her study 32 and $63 \%$ stress levels. For the lower stress level, a decrease of creep deformation was observed but no explanation could be given. It was suggested that a high fiber concentration in this specimen influenced stress redistribution and creep deformation.

This phenomenon is in contradiction with the definition of a creep deformation under constant stress for a non-ageing material.

Reinhardt \& Rinder [6], Rossi et al. [8], and Ranaivomanana et al. [7] also observed a decrease of creep deformation for cementitious materials loaded in tension. Atrushi [34] showed the decrease of total deformation in tensile creep test for HPC and that even under tensile loading the specimen contracts, and in this way associated this phenomenon to the influence of the driving force of shrinkage on the deformation process. It was pointed out that the order of magnitude for loaded and load-independent strain is similar, and recognized that the question of superposition of creep and shrinkage deformation in tensile creep testing is fundamental and needs to be analyzed.

A comparison of creep responses at early ages for normal strength concrete (NSC) and very high performance fibre reinforced concrete (HPFRC) has been presented in Rossi et al. [8]. The creep deformation values were negative (in the opposite direction than loading) for 1 out of 3 NSC specimens, which was explained by the existence of two mechanisms with opposite effect: (1) microcracking induced water transfer leading to additional self-drying shrinkage, (2) self-healing of NSC induced by the microcracking. However for HPFRC both tensile and compressive creep strains occurred in the direction of loading, for the age of loading at 7 days, and stress level of $30 \%$.

A comparison in Rossi et al. [42] made on concrete evokes that the basic creep in compression is more important than in tension, and that this difference increases for decreasing age of loading. This could be the confirmation of underestimating the tensile creep at early ages for cementitious materials.

Various literature sources report non-monotonic tensile creep strain evolution, for loading at various ages, both at early age and after 28 days. Some converge to the conclusion of a different apparent 
shrinkage under loading than on free specimen, either under sealed or partially drying conditions while others also mention the ongoing hydration and formation of new hydrates as a possible explanation.

Ranaivomanana et al. [7] performed compressive, tensile and bending creep tests on sealed High Strength Concrete specimen (average $71 \mathrm{MPa}$ compressive strength at 28 days), at various load levels at 28 days age. Shrinkage tests were realized with strain gages with $60 \mathrm{~mm}$ basis, on two different types of specimen $(100 / 100 / 500 \mathrm{~mm}$ and $70 / 70 / 280 \mathrm{~mm})$. Although it is not fully clear, it seems that for each batch, only one specimen was tested for each geometry. The scatter of the shrinkage measurements increased with age, up to $9 \mu \mathrm{m} / \mathrm{m}$ at 80 days considering all specimen and batches. This value is comparable to the average value at the same age, thus indicating a very large scatter, also compared to the total strains measured in the tensile creep tests. For a load level of $30 \%$, the tensile creep values obtained show an extremely large scatter with opposite trends, either increasing or decreasing. The same applies to a stress level of $40 \%$ with a somehow smaller scatter. For a $50 \%$ load level, the trend is clear between the two reported results with a decrease of creep strains after 30 days. For 30 and $40 \%$ load no systematic trend can be distinguished for the time at which decreasing creep strains occur. For a $50 \%$ load level, this point is slightly before 20 days. One should note that for all load levels the trend to a decrease of apparent tensile creep strains follows the scatter of the results: i.e. the more scatter, the more scatter in the trend to a decrease of creep strains. Finally, the scatter for the total strains in the tensile creep tests measured on each strain gauge for one specimen seems to influence the trend to decreasing tensile creep values. Specimen 1, with a load level of $30 \%$, exhibits a decrease of calculated tensile creep strains before 10 days, and a significant difference (close to $10 \mu \mathrm{m} / \mathrm{m}$ ) between the two values of the strain gauges whereas Specimen 2, for the same load level has very similar values of total strain for the two gauges and a trend to decreasing tensile creep strains only after 50 days. As such, the works presented in this paper should be confirmed by additional results with a larger number of specimen for shrinkage and creep measurements, taking into consideration the accuracy and scatter of the shrinkage and creep measurements under tensile loading. Nevertheless, the authors refer to discussions presented by Reinhardt \& Rinder [6] about the validity of the hypothesis that shrinkage measured on free and loaded in tension specimen are equal and to [43] 
where the explanation of additional drying shrinkage due to microcracking in loaded in tension specimens has been proposed.

Bournazel and Martineau [44] observed decreasing tensile creep on a Roller Compacted Concrete with a w/c $=0.1$, under a tensile stress of $0.2 \mathrm{MPa}$ (close to the tensile strength), at very early age (loading at $10 \mathrm{~h}$ ) under $20^{\circ} \mathrm{C}$ and $90 \% \mathrm{RH}$. The proposed explanation for the decreasing creep is the maturation of the material that induces internal unloading. Similar trends were found by Altoubat et al. [40] who investigated the creep response at very early age with incremental creep tests (loading age between 24 to 120 hours) on two concretes with $w / c=0.4$ and 0.5 , with or without fibers, under sealed or moistcovered conditions with a free and restrained test set-up (without temperature control). For a w/c ratio of 0.4, after interpretation with the solidification model from Bažant et al. [45] a clear trend of decreasing creep was observed at early ages, up to 27 hours. After these authors, the solidification theory can explain a non-monotonic creep in a time frame of fast development of hydration products.

This effect would be more pronounced at very early age and would be progressively offset and shifted in time with higher stress levels and increasing age, also for UHPFRC, following well the trends observed in the present study and by Kamen [18].

\subsection{Open question of shrinkage in free and loaded specimens}

A further explanation possible for the decrease of apparent tensile creep deformation is that shrinkage is not the same in loaded and unloaded specimen, meaning that the superposition principle is not valid. This leads to the hypothesis that the shrinkage value from a specimen loaded in tensile creep test is higher than from the free shrinkage one. This hypothesis was suggested also by Reinhardt \& Rinder [6] to explain the decrease of tensile creep deformation of HPC loaded with 0.8 stress/strength ratio, where in the initial part of test the tensile creep deformation decreases, and then changes tendency and increases. They present tensile creep tests at 28 days age, on High Strength Concrete up to C90/105, at various load levels up to $95 \%$ with non-monotonic evolution of tensile creep strains for two concretes (with higher strength) over three tested, during the first 200 days. After this period of time, apparent tensile creep strains come back to a more or less monotonic increasing trend. Between 5 and 7 
shrinkage tests were performed per concrete type. The specimens originally conditioned at $95 \% \mathrm{RH}$ were kept during the tests in plastic bags sealed around them, in a moist room with $65 \%$ RH. Plastic bags sealing is assumed not to provide a perfect sealing. Humidity measurements in the sealing bags show a decreasing RH with significant difference between loaded and free specimen, the later with a higher RH around them. Additionally, the strength after 2 years of non-failed, tensile creep loaded specimen was on average $10 \%$ higher than companion specimen kept unloaded. After the authors this indicates further hydration that corresponds to the larger RH drop observed in the plastic bags around the loaded specimen. The main conclusion of this study is that tensile loading is likely to induce internal RH changes significantly different from those occurring in free specimen and consequently a higher shrinkage under tensile loading. Experimental evidence of this hypothesis does not exist as it is not known how to measure the shrinkage evolution in a loaded specimen. However, the hygromechanical effect mentioned by Reinhardt et al. was experimentally demonstrated by Wyrzykowski et al. $[46,47]$ for compressive and tensile loading with an increase of the internal relative humidity under compressive loading and vice-versa under tensile loading, according to the seepage theory from Powers [48 ].

These findings support the mechanisms discussed by Rossi et al [8,43], according to which microcracking induced additional self-desiccation and later self-healing mechanisms under tensile loading as driving forces of the RH changes in loaded specimen would induce a different shrinkage under loading. They would be more significant in UHPFRC when water is still available in the pore structure, at very early age, and more pronounced for higher load levels which would trigger more microcracking.

More generally, Acker $[9,10]$ discussed in depth the underlying mechanisms of creep and shrinkage for cementitious materials and especially for UHPFRC. According to this author, ageing of creep is due to the previous consumption of viscous potential by shrinkage mechanisms and autogenous shrinkage is mostly the delayed viscous response to self-desiccation induced internal forces. Consequently, the significantly lower creep of UHPFRC compared to usual concretes is due to the very strong and fast development of autogenous shrinkage (due to their very low w/b ratio) at early 
age that uses a significant part of the viscous potential of the material to react to the forces due to selfdesiccation in the pore structure. Finally, according to Acker, creep and shrinkage share common underlying mechanisms linked to the viscous response of $\mathrm{CSH}$ and as such their usual separation is highly questionable.

\section{Conclusions}

An experimental campaign of early age UHPFRC tensile creep and relaxation tests at various stress levels, with single step or incremental loading was realized, with the objective to provide a better knowledge about the tensile viscoelastic response at early age and the onset of a non-linear viscous response (3 to 10 days):

- For all single creep tests, whatever the stress level, the instantaneous deformation was proportional to the imposed stress level, and was $20 \mu \mathrm{m} / \mathrm{m} / \mathrm{MPa}$ which corresponds to a modulus of elasticity of 50 GPa. Non-linearity was not observed in the phase of loading. The delayed deformation under constant stress was non-linear for two specimens tested with higher stress levels, and was of $6 \mu \mathrm{m} / \mathrm{m} / \mathrm{MPa}$ after $120 \mathrm{~h}$ from the instant of loading.

- For a very low stress level of $13 \%$ of $\mathrm{f}_{\mathrm{Ut}}$ the decrease of creep deformation was observed after $10 \mathrm{~h}$ from the instant of loading. This result was also observed by other authors for different cementitious materials. It highlights the difficulty to clearly separate volumetric changes (creep and shrinkage) occurring in cement based composites under loading and also to determine the tensile creep response at very low stress levels, with total strains of the same magnitude as those measured on free specimen.

- Relaxation tests with compensation of shrinkage by a real time closed-loop control were successfully performed for stress levels similar to creep tests both with single step and incremental loading.

- For higher stress levels (single step loading) at 60 and 90\%, increased relative relaxation were observed indicating a non-linear viscoelastic response. 
-In incremental tests, creep response showed a decrease of relative deformation for increasing stress levels until a non-linear threshold identified at 6.7 MPa. Similarly, stress relaxation was most pronounced for the first loading step, and then less and less pronounced for increasing stress levels, but a threshold for non-linear response was not observed, contrarily to single step relaxations performed at a similar age.

- The analysis of incremental relaxation tests showed that a non-ageing linear viscoelastic model fitted on the first loading step could predict the test results for all stress levels applied at the age of 3 days. - For low stress level in the linear viscoelastic domain, the viscoelastic potential obtained from creep and relaxation tests have the same range, for loading applied at the age of 3 days.

- Under imposed deformation corresponding to a stress of $2.7 \mathrm{MPa}(30 \%)$ at 3 days of age, the relaxation of stresses is significant, about $0.5-1 \mathrm{MPa}$ after $24 \mathrm{~h}$.

\section{Acknowledgements}

This project was financially supported by the Swiss National Science Foundation (grant 200021122253 ) and the European community through the $6^{\text {th }}$ FP project ARCHES. The precious help of Roland Gysler and Mohammad Hadi Kazemi Kamyab during the experimental works is gratefully acknowledged. 


\section{List of References}

[1] Denarié E., Brühwiler E., Cast-on site UHPFRC for Improvement of Existing Structures Achievements over the Last 10 Years in Practice and Research, Proc. HPFRCC7, (2015) 473-480.

[2] Kamen A., Denarié E., Sadouki H., Brühwiler E., Thermo-mechanical response of UHPFRC at early age - experimental study and numerical simulation, Cem. Concr. Res. 38 (2008) 822-831.

[3] Habel, K., Structural Behaviour of Elements Combining Ultra-High Performance Fibre Reinforced Concretes (UHPFRC) and Reinforced Concrete, Doctoral thesis, N³036, Ecole Polytechnique Fédérale de Lausanne, Switzerland, (2004).

[4] Habel K, Charron J-P, Denarié E, Brühwiler E., Autogenous deformations and viscoelasticity of UHPFRC in structures; Part I: experimental results and Part II: numerical modeling. Mag. Concr. Res. 58(3) (2006) 135-156.

[5] Kamen, A., Comportement au jeune âge et différé d'un BFUP écrouissant sous les effets thermomécaniques, Doctoral thesis, $\mathrm{N}^{\circ} 3827$, Ecole Polytechnique Fédérale de Lausanne, Switzerland, (2007).

[6] Reinhardt, H. and T. Rinder, Tensile creep of high-strength concrete, J. Adv. Concr. Tech. 4 (2006) 277-283.

[7] Ranaivomanana N., Multon S., Turatsinze A., Tensile, compressive and flexural basic creep of concrete at different stress levels, Cem. Concr. Res. 52 (2013) 1-10.

[8] Rossi, P., Charron J.P., Bastien-Masse M., Tailhan J-L., Le Maou F., and S. Ramanich, Tensile basic creep versus compressive basic creep at early ages: comparison between normal strength concrete and a very high strength fibre reinforced concrete, Mat. Struct. (2014) 1773-1785.

[9] Acker P., Micromechanical analysis of creep and shrinkage mechanisms, Proc. Concreep 6, (2001) $15-25$.

[10] Acker P., Swelling, shrinkage and creep: a mechanical approach to cement hydration, Mat. Struct. 37 (2004) 237-243.

[11] Parant, E., Mécanismes d'endommagement et comportements mécaniques d'un composite cimentaire fibré multi-échelles sous sollicitations sévères : fatigue, choc, corrosion, $\mathrm{Ph}$. $\mathrm{D}$. thesis, Laboratoire Central des Ponts et Chaussées - LCPC, France, (2003).

[12] Loukili, A. Etude du retrait et du fluage de Bétons à Ultra-Hautes Performances, Ph. D. thesis, Ecole Centrale de Nantes, France, (1996).

[13] Loukili, A; Richard,P and Lamirault,J; A Study on Delayed Deformations of an Ultra High Strength Cementitious Material, ACI SP-179, (1998) 929- 950.

[14] Cheyrezy M., Behloul M., Creep and Shrinkage of Ultra-High Performance Concrete, Proc. Concreep 6, (2001) 527-538.

[15] Acker, P. and Behloul, M., Ductal Technology: a Large Spectrum of Properties, a Wide Range of Applications, Proc. Int. Symp. on Ultra High Performance Concrete, Kassel, (2004) 11-24.

[16] Garas V. Y., Kahn F. L., Kurtis K. E., Short-term tensile creep and shrinkage of ultra-high performance concrete, Cem. Concr. Comp. 31 (2009) 147-152.

[17] Garas V. Y., Kahn F. L., Kurtis K. E., Creep of UHPC in tension and compression: Effect of thermal treatment, Cem. Concr. Comp. 34 (2012) 493-502. 
[18] Kamen A., Denarié E., Brühwiler E., UHPFRC tensile creep at early age, Mat. Struc. 42-1 (2009) 113-122.

[19] Switek. A, Denarié E., Brühwiler E., Tensile creep of UHPFRC under low and high stresses, Proc. ConMat 4, Nagoya, (2009) 432-437.

[20] Switek, A., Time-dependent response of Ultra High Performance Fibre Reinforced Concrete (UHPFRC) under low to high tensile stresses, Doctoral thesis $\mathrm{N}^{\circ} 4899$, Ecole Polytechnique Fédérale de Lausanne, Switzerland, (2011).

[21] Kazemi-Kamyab H., Autogenous Shrinkage and Hydration Kinetics of SH-UHPFRC under Moderate to Low Temperature Curing Conditions, Doctoral thesis, N5681, Ecole Polytechnique Fédérale de Lausanne, Switzerland, (2013).

[22] Rossi, P., A. Arca, E. Parant, and P. Fakhri, Bending and compressive behaviour of a new Cement composite, Cem. Concr. Res. 35-1 (2005) 27-33.

[23] Denarié, E., Habel K., Wuest J., SAMARIS deliverable D13, Report on preliminary studies for the use of HPFRCC for the rehabilitation of road infrastructure components, (2004), http://samaris.zag.si/.

[24] Denarié, E., Recommendations for the tailoring of UHPFRC recipes for rehabilitation, deliverable ARCHES D06, (2009), http://arches.fehrl.org/.

[25] Grosse C. U., Reinhardt H. W., Krüger M. Beutel R., Ultrasonic through-transmission techniques for quality control of concrete during setting and hardening, In: H.W.

Reinhardt, Editor, Advanced Testing of Fresh Cementitious Materials, Stuttgart (2006) 83-93.

[26] Denarié, E., Cécot. C, Huet. C., Caracterization of creep and crack growth interactions in the fracture behaviour of concrete, Cem. Concr. Res. 36 (2006) 571-575.

[27] Denarié, E., Etude expérimentale des couplages viscoélasticité-croissance des fissures dans les bétons de ciment, Doctoral thesis, $\mathrm{N}^{\circ} 2195$, Ecole Polytechnique Fédérale de Lausanne, Switzerland, (2000).

[28] Scrivener K.L., Backscattered electron imaging of cementitious microstructures: understanding and quantification, Cem. Concr. Comp. 26, (2004) 935-945.

[29] Stutzmann, P.E., Cement Clinker Characterization by Scanning Electron Microscopy, Cem, Concr., and Aggregate, 13, 2, (1991) 109-114.

[30] Bažant, Z. P., Numerical determination of long-range stress history from strain history in Concrete, Mat. Struct. 5-3 (1972) 135-141.

[31] Switek. A, Denarié E., Brühwiler E., Modelling of viscoelastic properties of UHPFRC under low to high tensile stresses, Proc. ConMod, Lausanne, Switzerland (2010)

[32] Bissonnette B., Pigeon M., Vaysburd A. M., Tensile Creep of Concrete: Study of Its Sensitivity to Basic Parameters, ACI Mat. Journal, (2007), 104, 4, 360-368.

[33] Bissonnette, B., Le fluage en traction: un aspect important de la problématique des réparations minces en béton, Ph.D. thesis, Université Laval, Québéc, (1996).

[34] Atrushi, D. S., Tensile and compressive creep of early age concrete: testing and modeling, Ph. D. thesis, The Norwegian University of Science and Technology, Trondheim, Norway, (2003). 
[35] Rossi, P., Godart, N., Robert, J.L., Gervais, J.P., and Bruhat, N., Investigation of the basic creep of concrete by acoustic emission, Mat. Struct. 27-9 (1994) 510-514.

[36] Gutsch, A. and F. Rostasy, Young concrete under high tensile stresses-creep relaxation and Cracking, Proc. Thermal Cracking in Concrete at Early Ages (1995) 111-116.

[37] Morimoto H., Koyanagi W., Estimation of Stress relaxation in Concrete at Early Age, Proc. Thermal Cracking in Concrete at Early Ages (1995) 95-102.

[38] Beushausen H., Masuku C., Moyo P., Relaxation characteristics of cement mortar subjected to tensile strain, Mat. Struct. 45, (2012) 1181-1188.

[39] Kovler K., Igarashi S.I., Bentur A., Tensile creep behavior of high strength concretes at early ages, Mat. Struct. 32 (1999) 383-387.

[40] Altoubat SA, Lange D. A., Tensile basic creep: measurements and behavior at early age. ACI Mater J 98 (5) (2001) 386-393.

[41] Østergaard, L., Lange, D.A., Altoubat, S.A., Stang, H., Tensile Basic Creep of Early age Concrete Under Constant Load, Cem. Concr. Res., 31, (2001) 1895-99.

[42] Rossi, P., Tailhan J.-L., Le Maou F., Comparison of concrete creep in tension and in compression: Influence of concrete age at loading and drying conditions, Cem. Concr. Res., 51 (2013) $78-84$.

[43] Rossi P., Tailhan J.-L., Le Maou F., Gaillet L., Martin E., Basic creep behaviour of concretes investigation of the physical mechanisms by using acoustic emission, Cem. Concr. Res., 42-1 (2012) $61-73$

[44] Bournazel, J. P., and Martineau, J. P., “A Laboratory Test to Analyze Creep under Tension of Young Concrete,” Proc. CONCREEP 5, (1993) 57-62.

[45] Bažant, Z. P., and Prasannan, S., Solidification Theory for Concrete Creep I: Formulation, ASCE J. Eng. Mech., 115, 8, (1989) 1691-1703.

[46] Wyrzykowski, M. and P. Lura. The effect of external load on internal relative humidity in concrete." Cem. Concr. Res. 65(0), (2014) 58-63.

[47] Wyrzykowski, M. and Lura P., RH Dependence upon Applied Load: Experimental Study on Water Redistribution in the Microstructure at Loading, Proc. CONCREEP 10, ASCE, (2015) 339-347

[48] Powers T. C., The thermodynamics of volume change and creep, Mater. Struct. 1 (1968) $487-$ 507. 


\section{FIGURES}

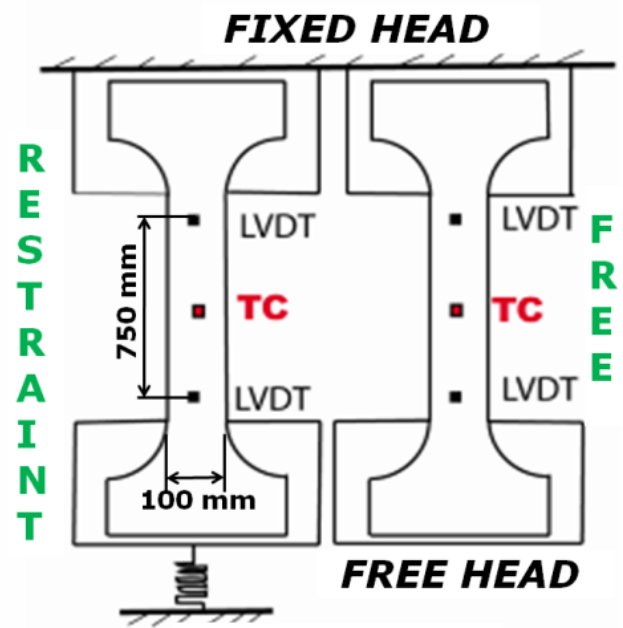

Fig. 1 TSTM testing setup with TC: Thermocouple, LVDT: Displacement transducer, taken from [5]

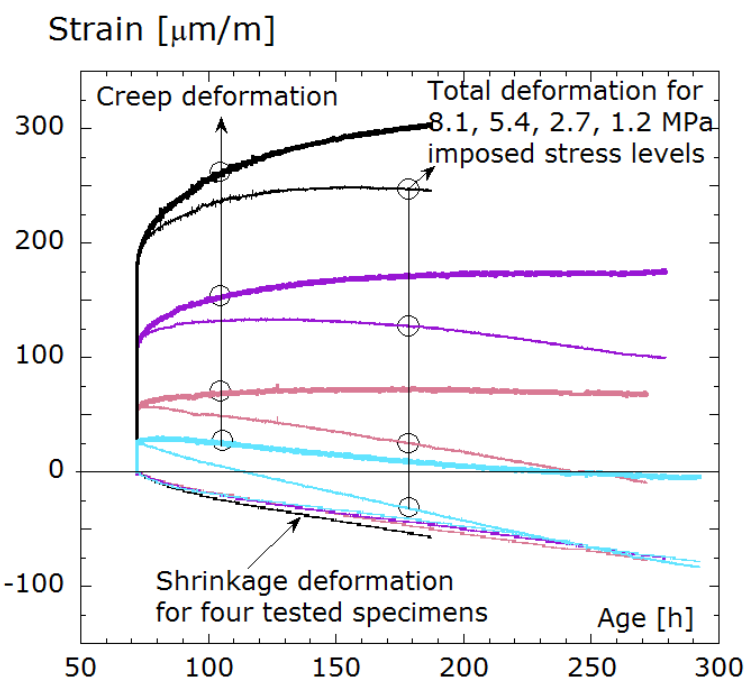

Fig. 2 Total, shrinkage and creep deformation for four load levels, specimen FL_3 : 1.2 MPa, FL_8 : 2.7 MPa, FL_9 : 5.4 MPa and FL_11:8.1 MPa 


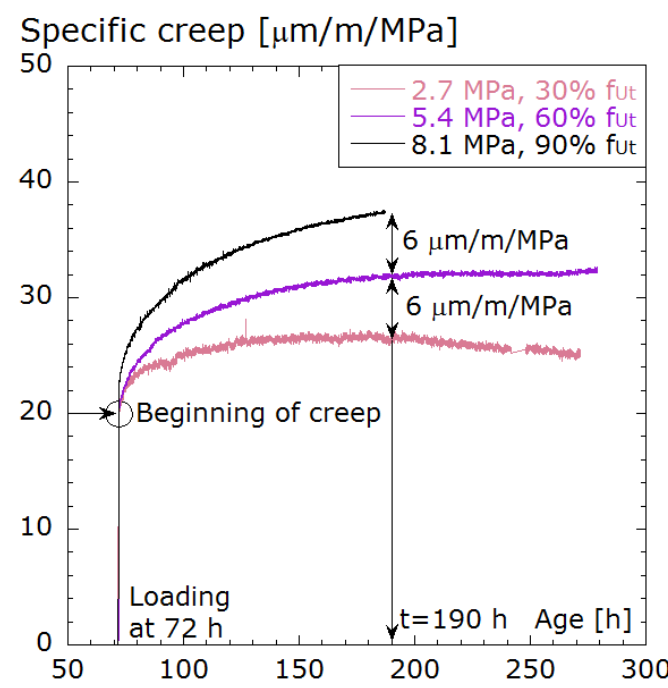

Fig. 3 Individual specific creep results from $72 \mathrm{~h}$ age; specimens : FL_8, FL_9, FL_11, fu,t: average quasi-static tensile strength at 3 days age.

a)

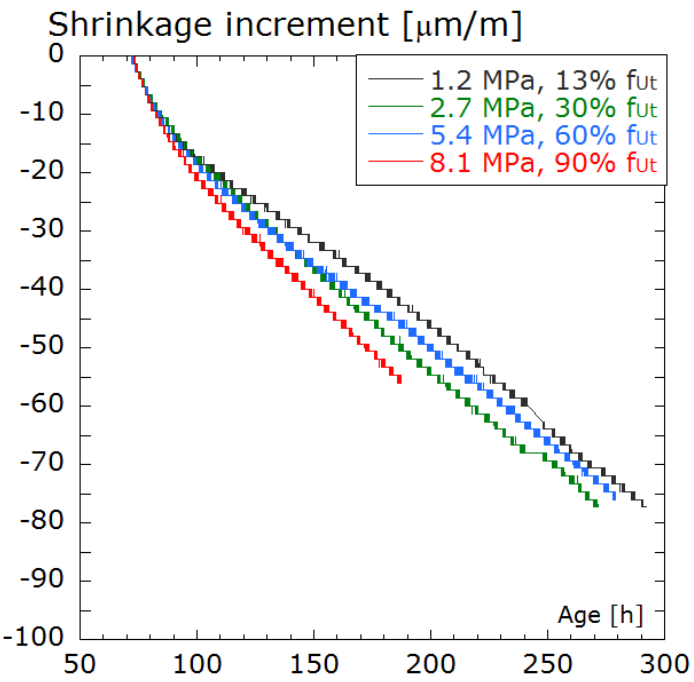

b)

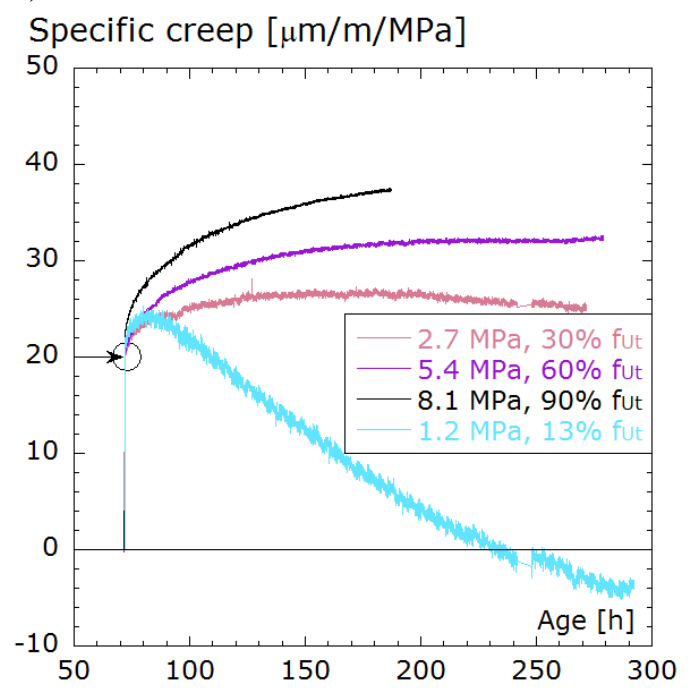

Fig. 4 a) Shrinkage since the instant of loading and b) specific creep for four stress levels in TSTM, specimens : FL_3, FL_8, FL_9, and FL_11, f 
a)

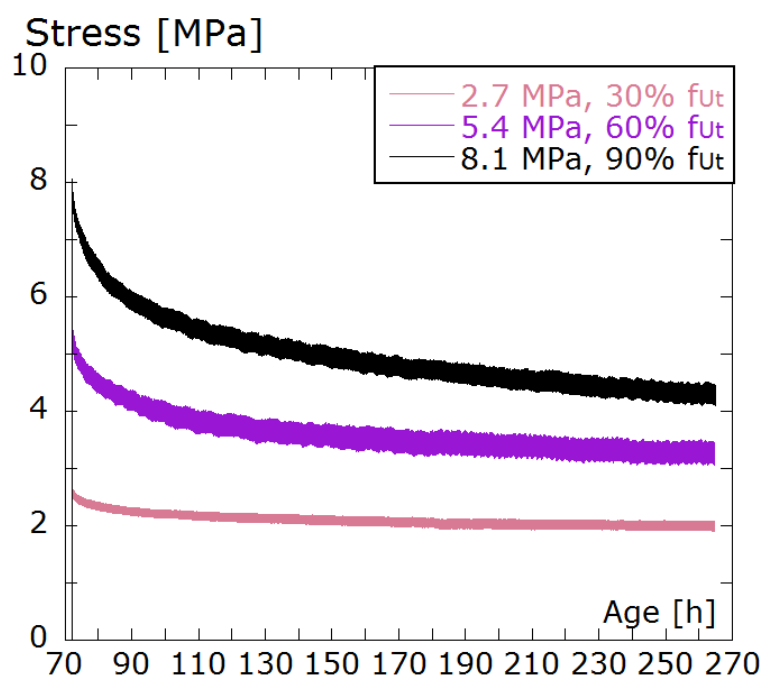

b)

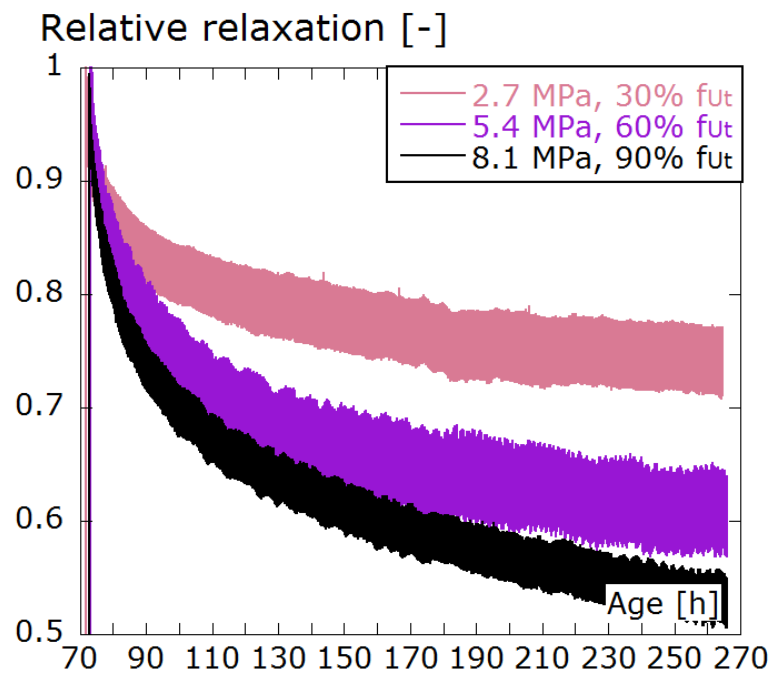

Fig. 5 a) Absolute and b) relative relaxation, specimens loaded at 30\%:FL_19, 60\%:FL_15, and $90 \%:$ FL_16, $\mathrm{f}_{\mathrm{U}, \mathrm{t}}$ : average quasi-static tensile strength at 3 days age.

a)

\section{Stress [MPa]}

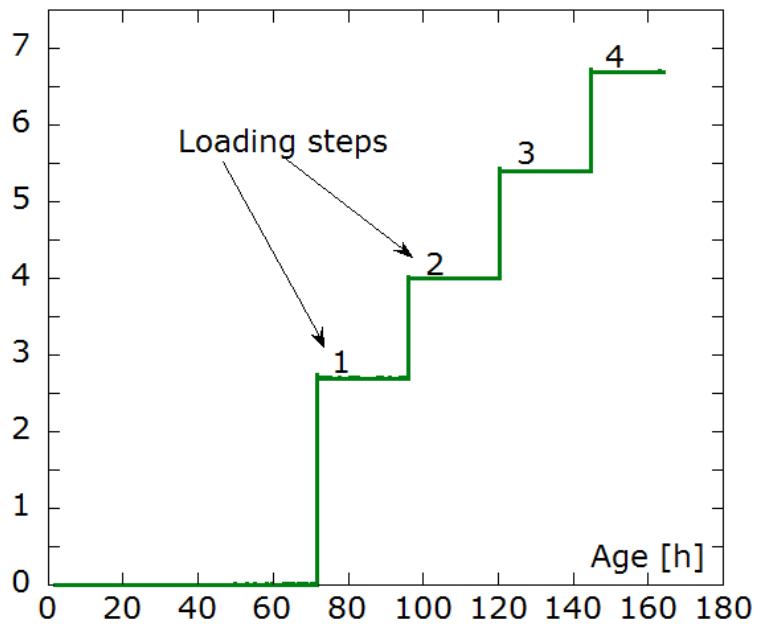

b)

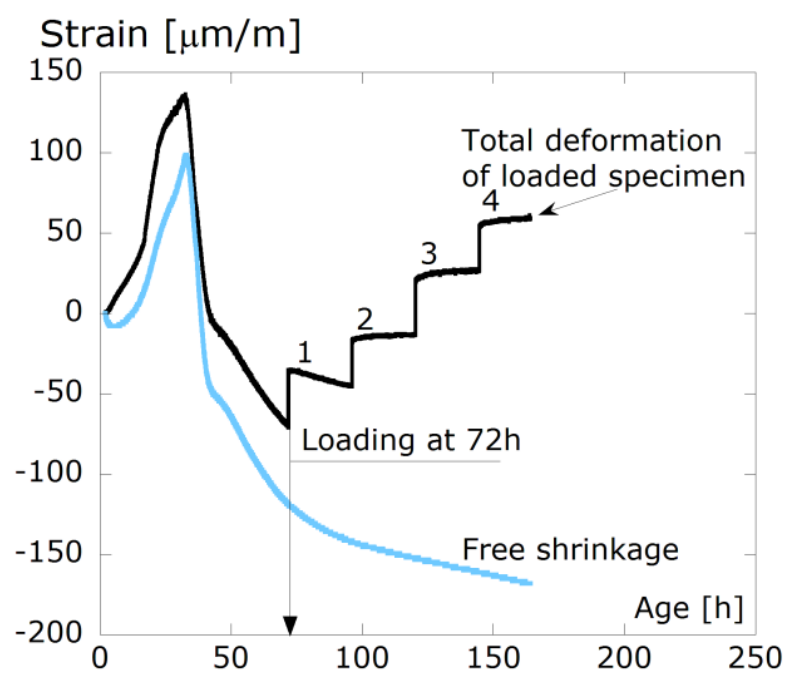

Fig. 6 Incremental tensile creep in TSTM for specimen FL_21, a) loading steps, and b) shrinkage and creep response 
a)

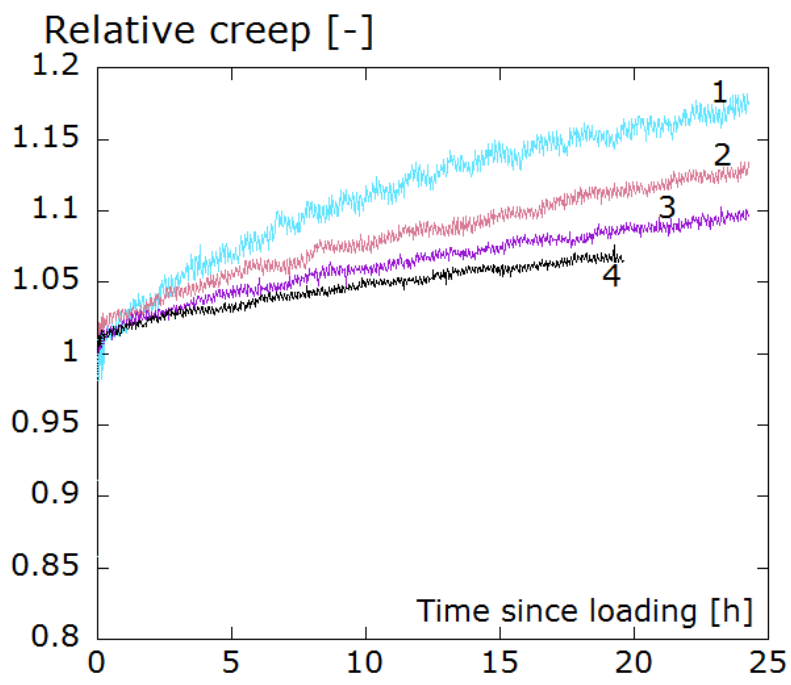

b)

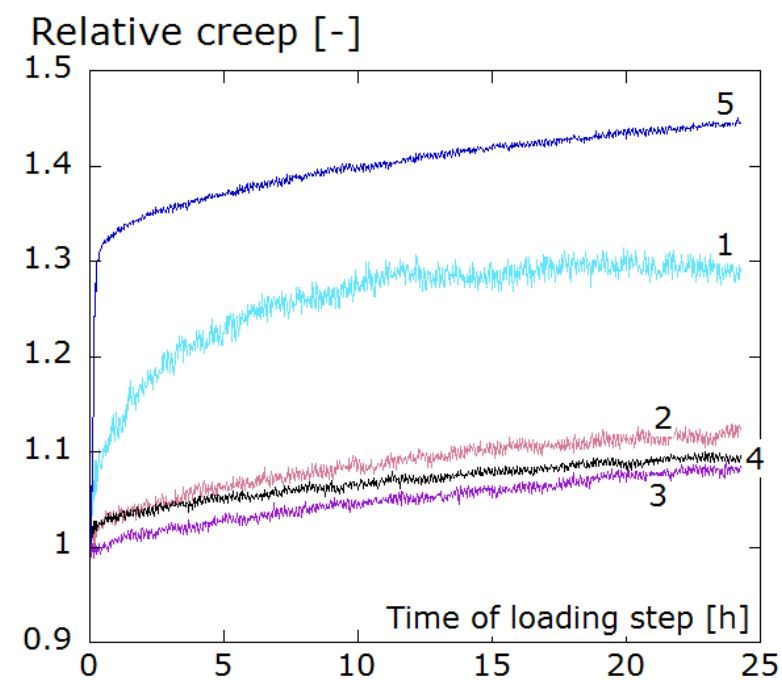

Fig. 7 Relative creep responses in incremental test, specimens a) FL_21 and b) FL_24

a)

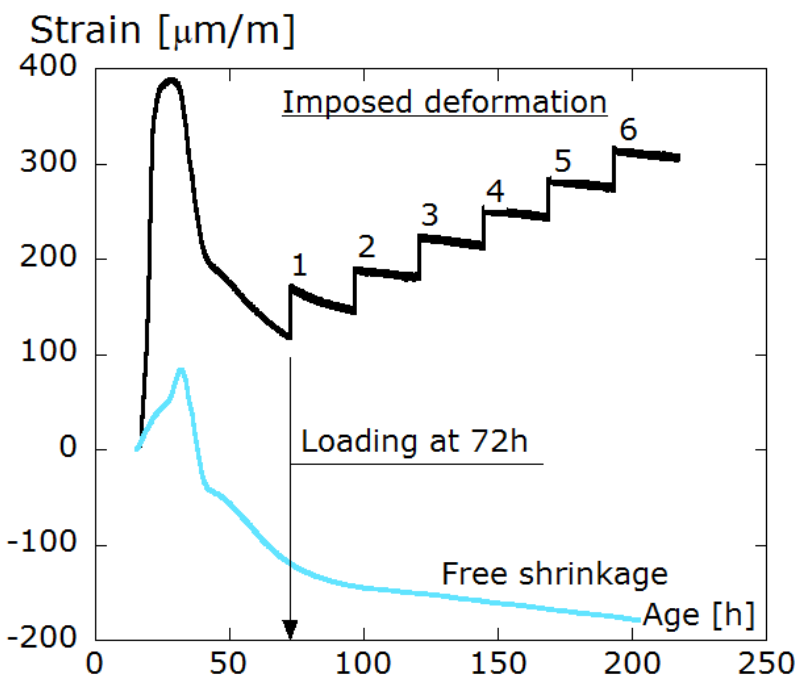

b)

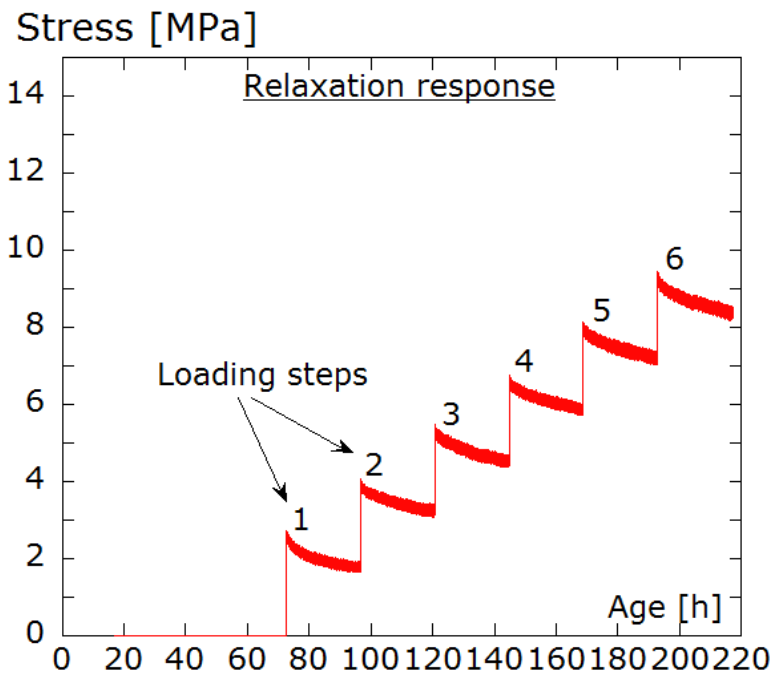

Fig. 8 Incremental tensile relaxation test in TSTM at 3 days of age for specimen FL_22, a) free shrinkage and imposed deformation, b) absolute stress relaxation response 


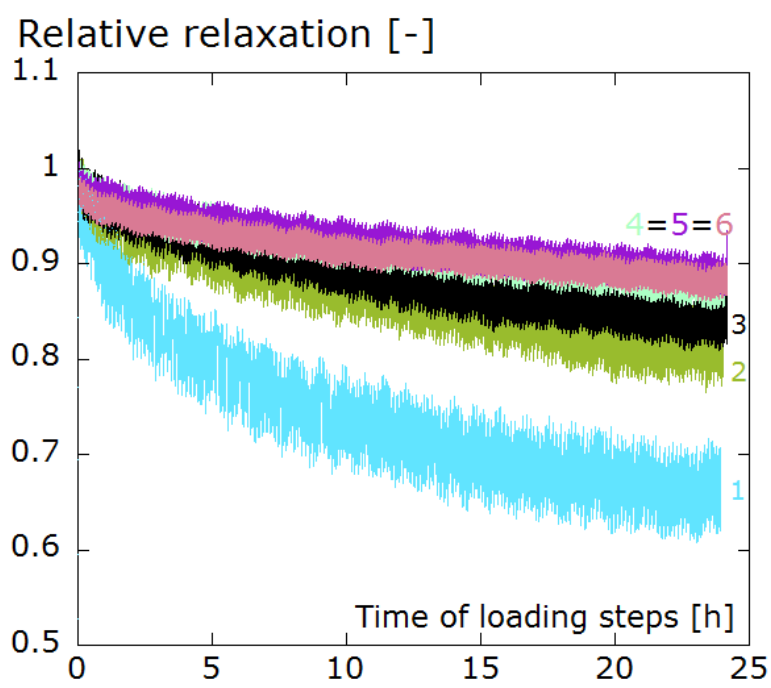

Fig. 9 Relative stress relaxation response in incremental test, specimen FL_22

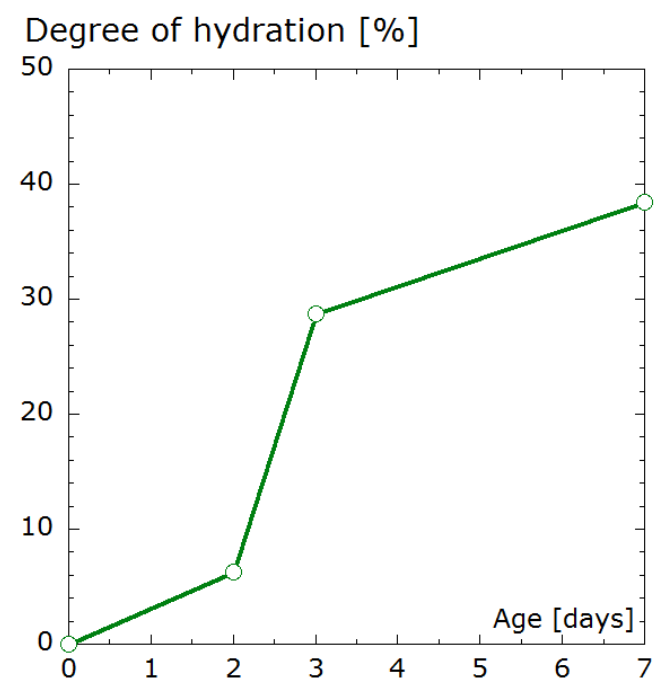

Fig. 10 Degree of hydration 
Relative creep [-]

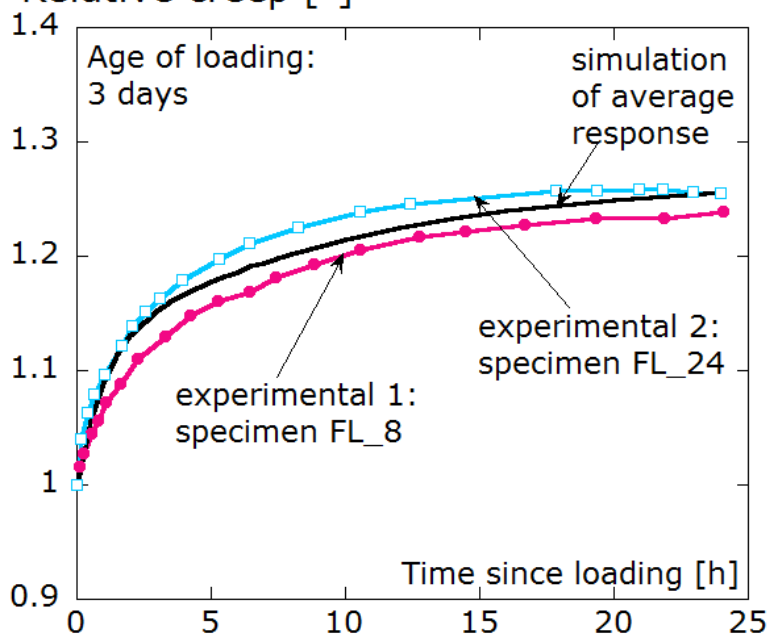

Fig. 11 Experimental and modeled creep response loaded at 3 days up to 30\% of strength at 3 days

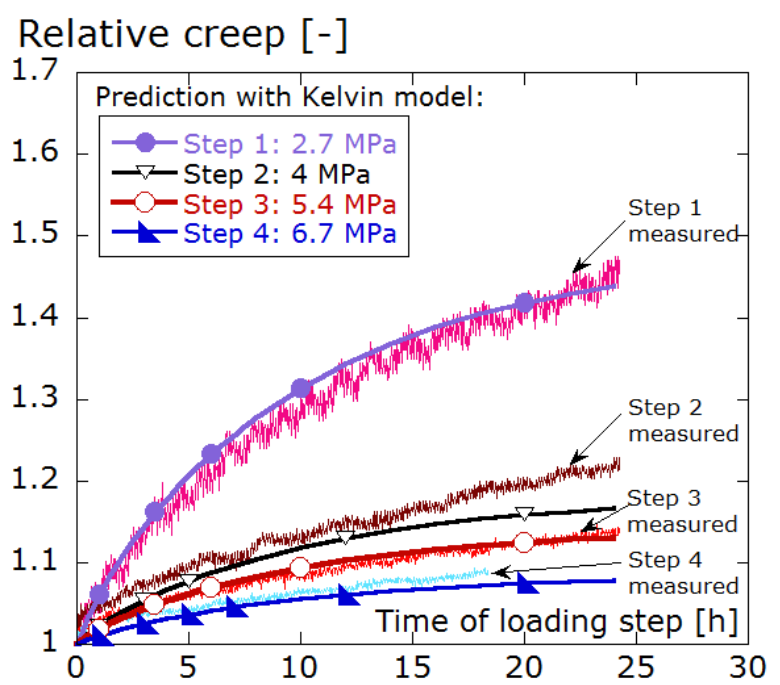

Fig. 12 Experimental and modeled incremental creep test, specimen FL_21 
a)

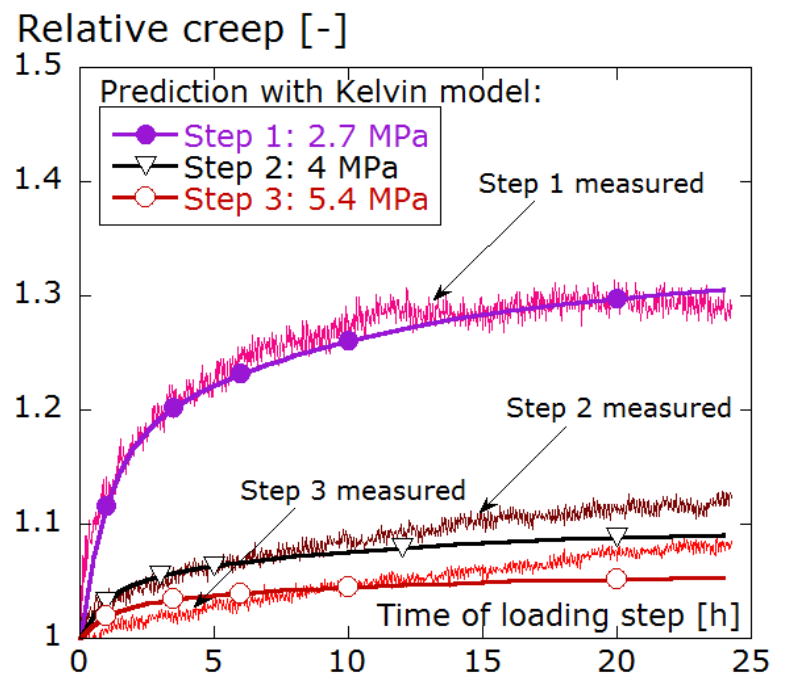

b)

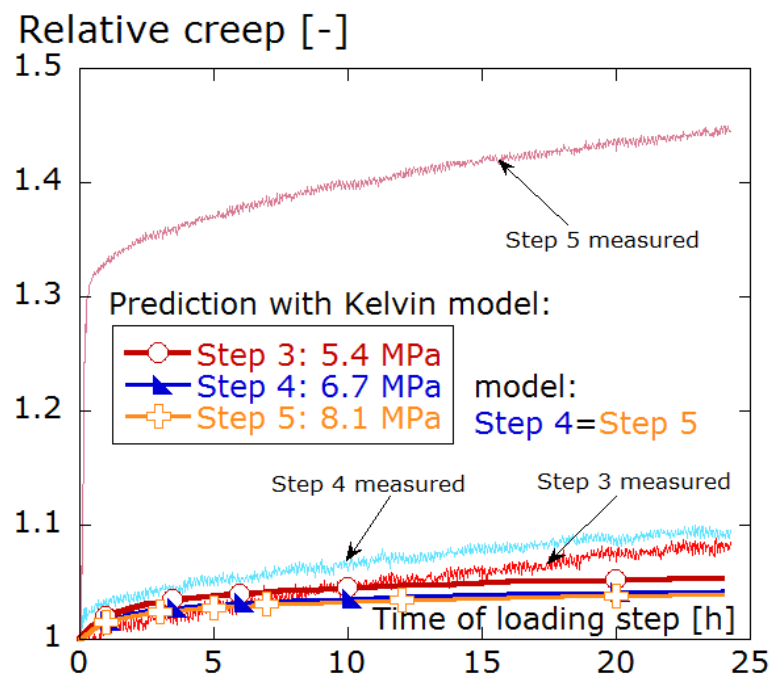

Fig. 13 Experimental and modeled incremental creep test, specimen FL_24 a) steps 1-3, b) steps 3-5

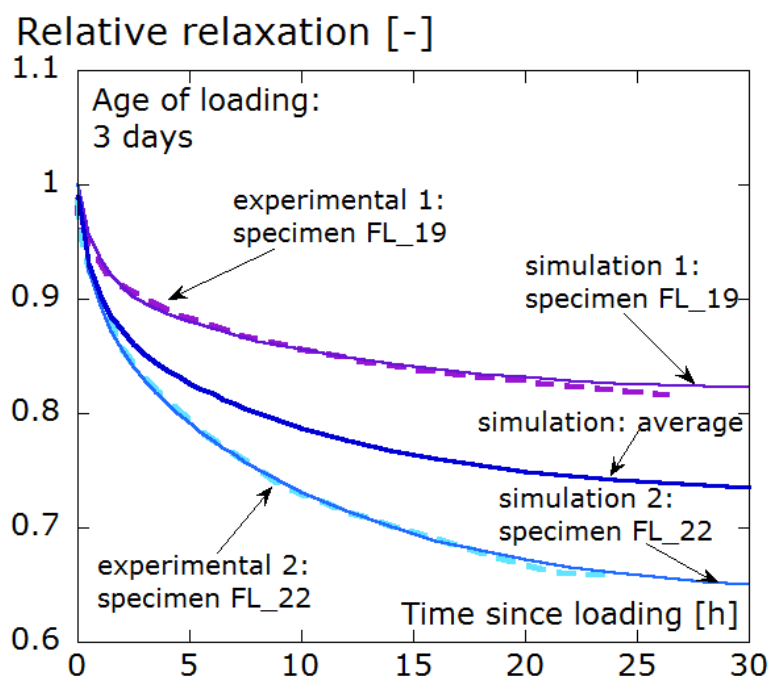

Fig. 14 Experimental and modeled relaxation response at 3 days, specimens FL_19 and FL_22 
a)

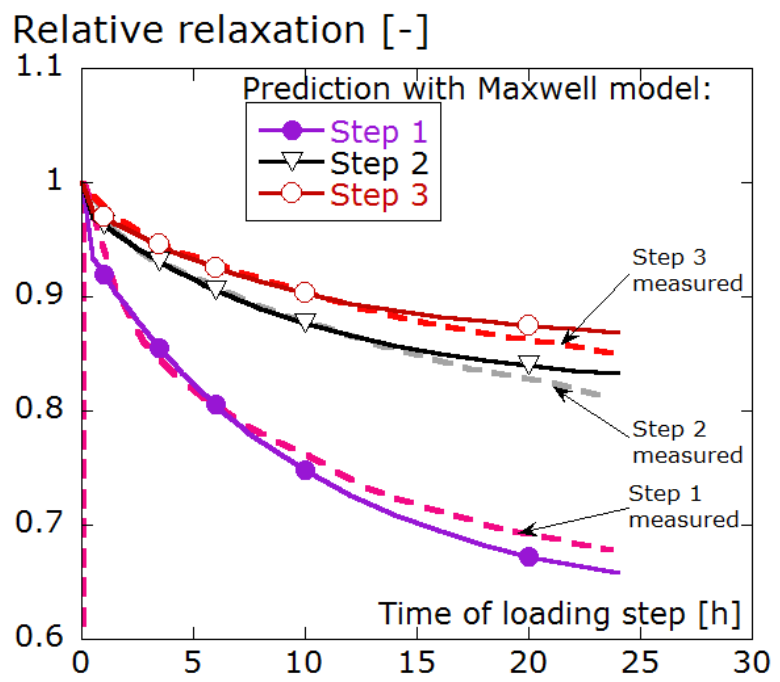

b)

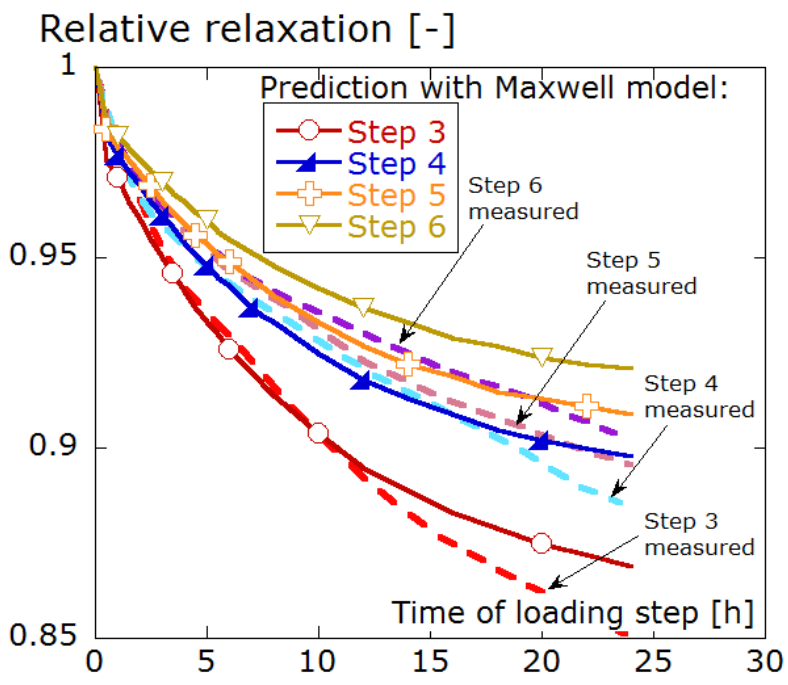

Fig. 15 Experimental and modeled incremental relaxation at 3 days, specimen FL_22, a) steps 1-3, and b) steps 3-6

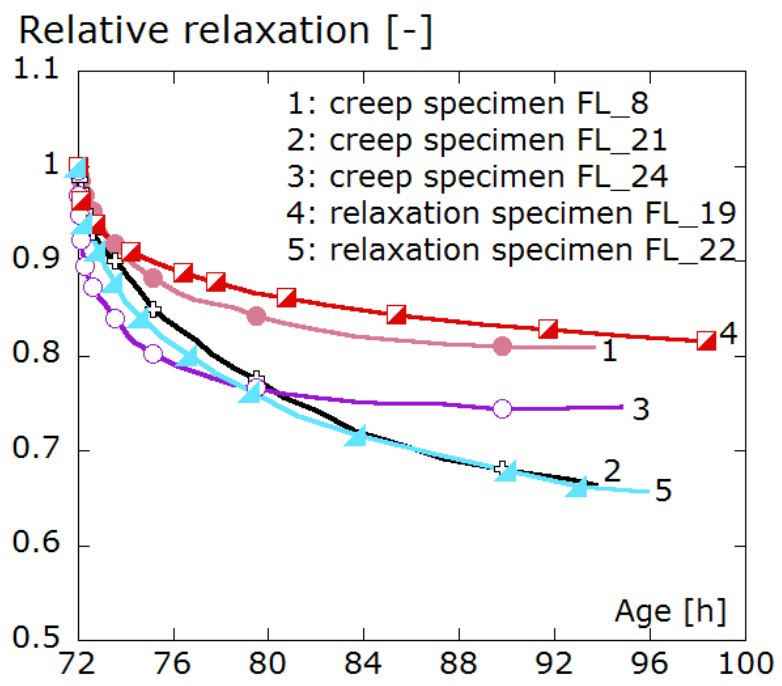

Fig. 16 Stress relaxation from relaxation tests and predicted from creep tests at 3 days at $30 \% \mathrm{f}_{\mathrm{U}, \mathrm{t}, 3}$ 


\section{TABLES}

Table 1 Stress levels for creep test in TSTM setup

\begin{tabular}{|c|c|c|c|c|}
\hline $\mathrm{N}^{\circ}$ & Name of specimen & Stress level & Stress level [\% $\left.\mathrm{f}_{\mathrm{U}, \mathrm{t}}\right]$ & Stress level [MPa] \\
\hline 1 & FL_8 & Low & $30 \%$ & 2.7 \\
\hline 2 & FL_9 & Medium & $60 \%$ & 5.4 \\
\hline 3 & FL_11 & High & $90 \%$ & 8.1 \\
\hline 4 & FL_3 & Very Low & $13 \%$ & 1.2 \\
\hline
\end{tabular}

$\mathrm{NB}: \mathrm{f}_{\mathrm{U}, \mathrm{t}}$ : average quasi-static tensile strength at 3 days age.

Table 2 Load levels for incremental tensile creep and relaxation test

\begin{tabular}{|c|c|c|c|}
\hline $\mathrm{N}^{\circ}$ & Stress level [\% $\left.\mathrm{f}_{\mathrm{U}, \mathrm{t}}\right]$ & Stress levels [MPa] & Duration of loading step [h] \\
\hline 1 & 30 & 2.7 & 24 \\
\hline 2 & 44 & 4 & 24 \\
\hline 3 & 60 & 5.4 & 24 \\
\hline 4 & 74 & 6.7 & 24 \\
\hline 5 & 90 & 8.1 & 24 \\
\hline 6 & 105 & 9.5 & 24 \\
\hline
\end{tabular}

$\mathrm{NB}: \mathrm{f}_{\mathrm{U}, \mathrm{t}}$ average quasi-static tensile strength at 3 days age.

Table 3 Parameters for generalized Kelvin model for creep response at 3 days

\begin{tabular}{|c|c|c|c|c|}
\cline { 2 - 5 } \multicolumn{1}{c|}{} & Chain & 1 & 2 & 3 \\
\cline { 2 - 5 } \multicolumn{1}{c|}{} & $\tau_{\mathrm{k}}[\mathrm{h}]$ & 0.1 & 1 & 10 \\
\hline Set 1 & $\mathrm{E}_{\mathrm{k}}\left(\mathrm{t}_{0}\right) / \mathrm{E}_{\text {tot }}\left(\mathrm{t}_{0}\right)$ & 0 & 0.12 & 0.15 \\
\hline Set 2 & $\mathrm{E}_{\mathrm{k}}\left(\mathrm{t}_{0}\right) / \mathrm{E}_{\text {tot }}\left(\mathrm{t}_{0}\right)$ & 0.03 & 0.45 & 0 \\
\hline
\end{tabular}

Table 4 Parameters of generalized Maxwell model for average relaxation response at 3 days

\begin{tabular}{|c|c|c|c|c|c|}
\hline Chain & 1 & 2 & 3 & 4 & 5 \\
\hline$\tau_{\mathrm{i}}[\mathrm{h}]$ & 0.1 & 1 & 10 & 100 & 10000 \\
\hline $\mathrm{E}_{\mathrm{i}}\left(\mathrm{t}_{0}\right) / \mathrm{E}_{\mathrm{tot}}\left(\mathrm{t}_{0}\right)$ & 0.02 & 0.07 & 0.18 & 0 & 0.73 \\
\hline
\end{tabular}

